\title{
EARTHQUAKE RESPONSE OF NUCLEAR REACTOR BUILDING DEEPLY EMBEDDED IN SOIL
}

\author{
T. MASAO, Y. TAKASAKI \\ Fujita Corporation, Nuclear Power Plant Civil \& Architecture Department, \\ Kohoku-ku Yokohama 223, Japan \\ S. YAMAMOTO, Y. KOORI \\ Chiyoda Chemical Engineering \& Construction Corporation, \\ Technical Research Laboratory, Ikegaminita Kawasaki 210, Japan
}

SUMMARY

This paper is the further report of the previous SMiRT-4 paper $K 2 / 7$ in which dynamic behavior by oscillator of deeply embedded model was described. In the previous report, variotion of resonant frequencies and domping ratios for various embedded depth were mainly described. As for these results, radiational damping became to great with embedment of building. In this paper, earthquake observation and analytical investigations during earthquake are presented.

Earthquake observation was performed on the cubic model (a size was $5 \times 5 \times 5$ meters which was overlied after forced vibration tests, weight was 240 tons) made of concrete, and base of model was underlie 3.75 meters under the ground. Accelerations were measured at the top of model, ground surface and in ground. And earth pressure were measured at the bottom and side of model.

To explain the results of earthquake observation, we used two analytical methods. One was lumped mass method and the other was finite element method with transmitting boundary. Lumped mass method was performed under the following assumptions. (1) Free field soil was modeled by mass and shear spring system. (2) To feed acceleration to base of model, free field motion of same level on base of model was adopted. (3) To consider the interactiv effects between soil and side wall of model, resistances that were in proportional to relative velocity and displacement were used. As to the finite element method with transmitting boundary, it was modeled as follows. (1) Irregular zone was modeled by quadrilateral axisymmetric elements by nonaxisymmetric load. (2) Layered zone was modeled by axisymetric element by nonaxisymetric load with transmitting boundary, and materials were linearly viscoelastic media. (3) Domping was modeled by complex stiffness moduli.

From the results of observational and analytical studies, it was found that (1) the shapes of the time histories by analyses agree with them by observation, but the maximum acceleration by analyses were a little greater than them by observation, (2) the response spectra by analyses good agree with them by abservation in both the shape and value. Additionaly, there were no significant differences between lumped mass method and finite element method with transmitting boundary in seismic response.

As a conclution, both the observational and analytical studies indicate that the embedment has an effect of increase of radiational damping on the seismic response of deeply embedded structure such as nuclear reactor building. And it is indicated that the analytical method in this paper are ovailable procedures for such case. 


\section{INTRODUCTION}

This paper discusses the interaction between dynamic soil and the nuclear reactor building structure deeply embedded in soil, and studys the dynamic behavior of a prototype model for forced vibration and its earthquake respanse. The dynamic behavior was already portialy presented at the 4th SMiRT (K2/7).

The test results are evaluated from the following points of view:

1) Increase in stiffness and radiational damping according to depth of embecment.

2) Variation in earth pressure according to depth of embecment.

3) Response of prototype model for forced oscillation and earthquake.

4) Comparison between test results and analysis.

\section{OUTLINE OF EXPERIMENT}

\subsection{SOIL PROFILE OF SITE}

The soil of the test site is uniform clay with a standard penetration $\mathrm{N}$ value of 10 and hard rack with an $\mathrm{N}$ value exceeding 50 underneath. Physical parameters of the test site are shown in Fig.1. The first natural frequency of the shear mode of clay calculated by using physical parameters coincide with the predominant frequency of microtremors measured on the surface of the soil.

\subsection{OUTLINE OF TEST MODEL}

The test model used for the forced vibration test is shown in Fig.2. The model has an area of $5 \times 5$ square meters, a height of 3.75 meters and a total weight of 169 tons. Earth pressure transducers are installed on the sides and the bottom of the model. Both normal force and shearing force operating on the model during the test are measured by these transducers. After the forced oscillation test, the height of the test model is increased to 5 meters and accordingly, the total weight becomes 242 tons.

\section{TEST RESULTS FROM FORCED EXCITATION}

\subsection{FREQUENCY RESPONSE AT EACH EMBEDDED DEPTH}

The frequency responses of horizontal displacement, vertical displacement on the top surface of the test model, the normal earth pressure on the bottom surface, and shearing earth pressure on the bottom surface of the test model are shown in Fig. 3 thru 6. It is observed from these that the amplitudes of resonance peak become small and the resonance frequency becomes high as the embedded depth increases in each case. It is also observed that the forced oscillation does not excite the first natural mode of the surface soil layer with a natural frequency of $4 \mathrm{~Hz}$.

\subsection{DISTRIBUTION OF EARTH PRESSURE AT RESONANT FREQUENCY}

The distribution of normal pressure and shearing pressure on the bottom, and normal pressure and shearing pressure on the sides are shown in Fig.7 thru Fig.10.

\section{CALCULATION METHOD}

4.1. LUMPED MASS MODEL (L.M.M.)

The lumped mass model of horizontal and rotational spring with a dash-pot is shown in Fig.11. The earthquake ground motion calculated from the one dimensional model assuming a free field ground motion is input to each spring and dash-pot. 


\subsection{FINITE ELEMENT MODEL( F.E.M.)}

The axi-symmetric finite element model with an energy transmltting vertical boundary is shown in Fig.12. The material damping of the soll used is assumed as $5 \%$ of critical damping ratio.

\subsection{CYLINORICAL RIGID BODY MODEL(C.R.M.)}

The dynamic analytical model of a cylinder embedded in elastic media which is infinite in the horizontal direction and has a horizontal boundary beneath the bottom of the model is shown in Fig. 13 .

\section{VARIETY OF RESONANT FREQUENCY AND EQUATED DAMPING FACTOR AGAINST EMBEDMENT}

\subsection{RESONANT FREQUENCY}

Fig.14 shows the calculated results of resonant frequency changes caused by increasing the embeded depths. All the calculated values are larger than the experimental ones. However, in both cases, slopes of resonont frequency curves begin to slow down oround half embecment.

\subsection{EQUATED DAMPING FACTOR}

Fig. 15 shows results of domping factor change with embedded depth, obtained from both experiments and calculations. Both experimental and calculoted results show that the damping factor increases abruptly at half embedment. The calculation of this damping factor was made from three points of the resonant frequency curves.

\section{RESPONSE DURING EARTHQUAKE}

\subsection{TIME HISTORY RESPONSE}

Fig.16 shows the calculated and recorded results of time history response caused by an input GL-12 meters. Magnitude, epicentral distance and focal depth of this earthquake were $4.445 .7 \mathrm{~km}$ and $20 \mathrm{~km}$, respectively. L.M.M. and F.E.M. almost coincided with each other on moximum velocity and wove from history, and all the calculated values are larger than the recorded ones. It is assumed that wave motion used in colculation at GL-12 meter is SH wove, but exactly, recorded waves for input containe several kind of waves, for instance body waves of SV and $P$ or Surface waves. Especially considering the component of surface wave, because of incoming from lateral side of model, calculated results against SH wave may be abnormal conclution. However since it is very technically difficult to separate by kinds of motion, now input of earthquake loading is treated as a SH wave. In case of comparative near field earthquake, wave travels keeping some angle against vertical axis. For the calculated methods presented here, above effect is not considered. As for exact recorded response of model, when earthquake motion is given in some direction, out put response is observed a little in other transverse direction by reason of unsymetrical form of model. This effect is ignored in calculation.

\subsection{RESPONSE SPECTRA}

Fig. 17 shows response spectra of previous time history. Locations of main peaks of calculated and recorded waves are found at the first natural frequency of ground. Natural frequency caused by interaction between soil and testing model was $8 \mathrm{~Hz}$. No effect could be seem in the recorded waves, while insignificant disturbance was obtained from calculations. The difference of calculation methods hardly gave any difference as in the time history response. The height of response spectro at peak frequency and other frequency 
points are almost same in between recorded results and both of calculation. Maximum values for using of calculation of response spectra are keeped the same in Fig. 16.

\section{CONCLUSION}

1) Results from experiments and calculations show that radiational domping increases with the embedded depth remarkably.

2) Concerning response during earthquake motion, such a distinct resonant peak could not be observed as in the case of the forced vibration test.

3) The structural response to earthquake is mainly derived from the surrounding ground vibration.

4) Calculation methods gave little difference. In a simple lumped mass system in particular, a model like Fig. 11 is desirable to evaluate effects from ground vibration.

5) The center of gravity is supposed to rise, if there is a considerable tall structure on the base. It is presumed that rocking motion is increased, which means the interaction between soil and structure will manifest itself.

\section{ACKNOWLEDGEMENT}

This research was financially supported by Japan Science \& Technology Agency. The authors wish to express their wishes to the chair man Dr. Yorihiko OHSAKI and other members of special cormiter organized in Archtectural Institute of Japan for promoting this research.

\section{REFERENCES}

11/ T.MASAO, M.HIRASAWA, S.YAMAMOTO, Y.KOORI "Earthquake Response of Nuclear Reactor Building Deeplt Embedded in Soil", Proceeding 4th. SMiRT , Sanfrancisco, U.S.A.,15-19 August 1977, K2/7,

/2/ T.MASAO, M.HIRASAWA, Y. TAKASAKI, M. OKA J IMA, S. YAMAMOTO, E. KAWADA, Y, KOOR I S.OCHIAI,N.SHIMIZU, "Experimental Study on Vibrational Characteristics of Deeply Embedded Footing", Proceedings of The Fifth Japan Earthquake Engineering Symposium-1978, PP 409-416

/3/ T.MASAO," Dynomic Behabior of Interaction between Soil and Cylindrical Rigid Body", Proceedings of The Fifth Japan Earthquake Engineering Symposium-1978 Nov. Tokyo, Japan, pp 393-400.

14/ T.MASAO, S.YAMAMOTO "Report of Japan Science \& Technology Agency $1976 "$ Tokyo Japan 


\begin{tabular}{|c|c|c|c|c|c|}
\hline lepth & $\begin{array}{c}\text { boring } \\
\log \end{array}$ & $\begin{array}{l}\text { ilump- } \\
\text { ling } \\
\text { pt. }\end{array}$ & $\begin{array}{l}\text { standird } \\
\text { pentetration }(N) \\
\text { test result }\end{array}$ & $\begin{array}{l}\text { reloei ty }(\mathrm{n} / \mathrm{u}) \\
\mathrm{V} \& \mathrm{~V}, \mathrm{Vp}(\end{array}$ & $\begin{array}{l}\text { density } \\
(\mathrm{g} / \mathrm{cm})\end{array}$ \\
\hline model & $\begin{array}{c}\text { kwanto } \\
\text { loam }\end{array}$ & 300 & 20 304050 & 150 600 & 1.478 \\
\hline & elay loem & 3.71 & & $180 \div 900$ & 1.427 \\
\hline $5 \mathrm{~m}$ & $\begin{array}{l}\text { clay } \\
\text { clay loam }\end{array}$ & 600 & & & \\
\hline \multirow{4}{*}{$10 \mathrm{~m}$} & $\begin{array}{l}\text { andy } \\
\text { clay }\end{array}$ & $\begin{array}{l}6.61 \\
9.00 \\
\end{array}$ & & $\begin{array}{cc}230 & 1700 \\
& \vdots\end{array}$ & 1.376 \\
\hline & silt & 9.76 & & 1200 & 1.590 \\
\hline & and & 1200 & & & \\
\hline & $\begin{array}{l}\text { hardy } \\
\text { c lay }\end{array}$ & 1215 & & & 1.474 \\
\hline
\end{tabular}
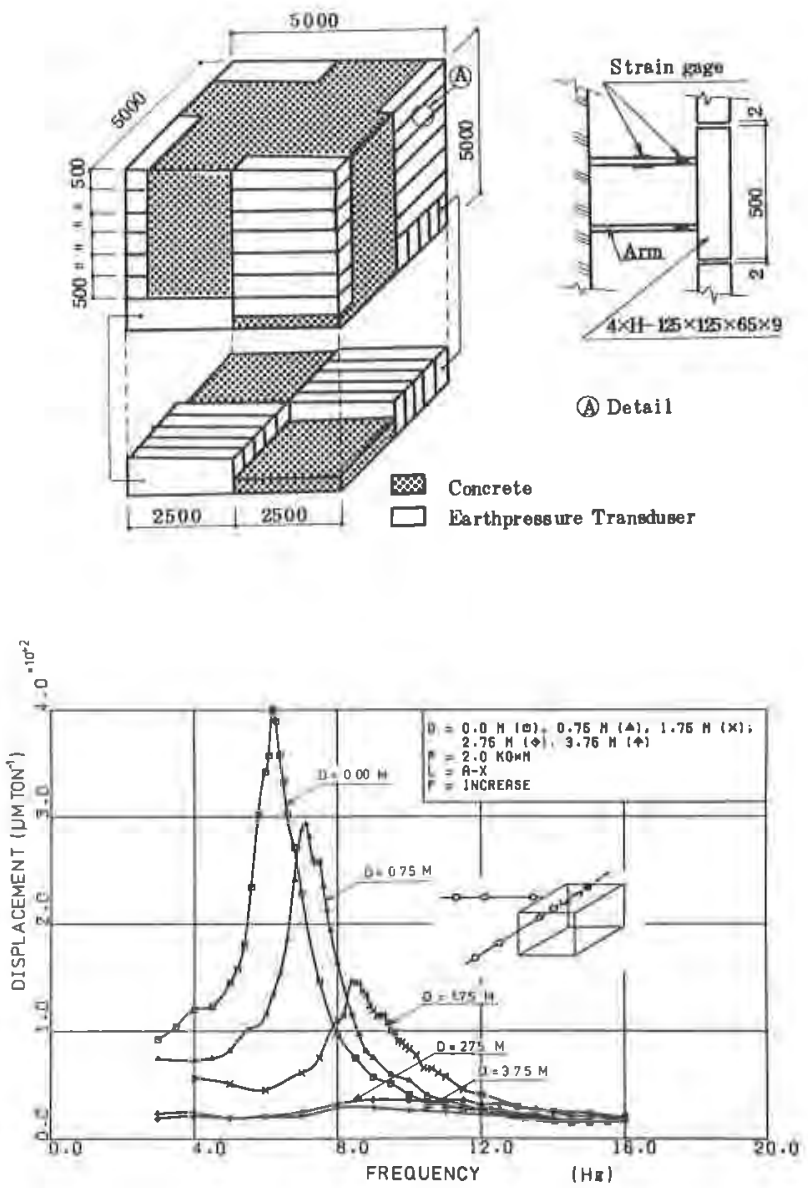

Fig.l Soil profile of site.

Fig. 2 Testing model for forced vibration overlaid as a ear thquake observation.

Fig.3 Horizontal frequency response by forced vibration test at the top of model. 


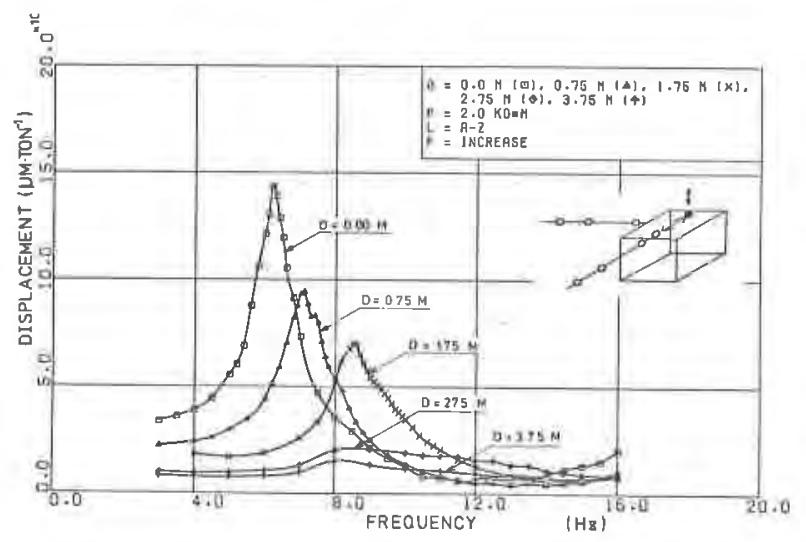

Fig. 4 Vertical frequency response by forced vibration test at the top of model.

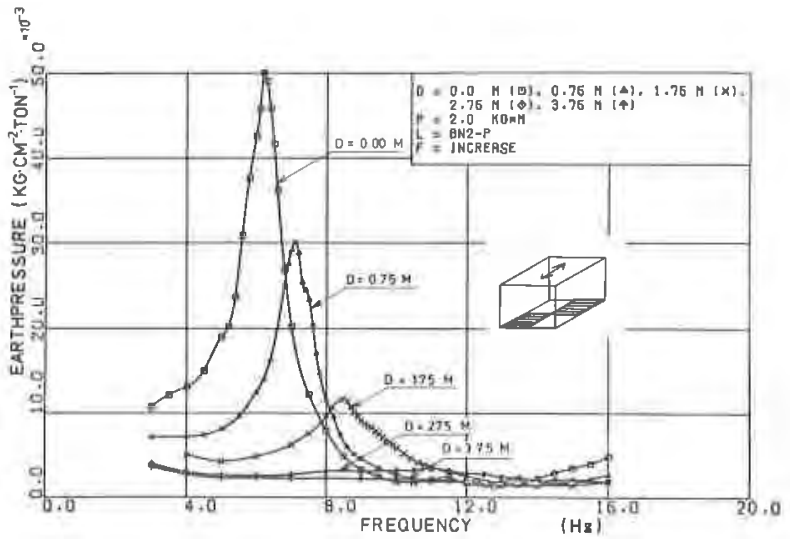

Fig.5 Normal earth pressure response curves at botton.

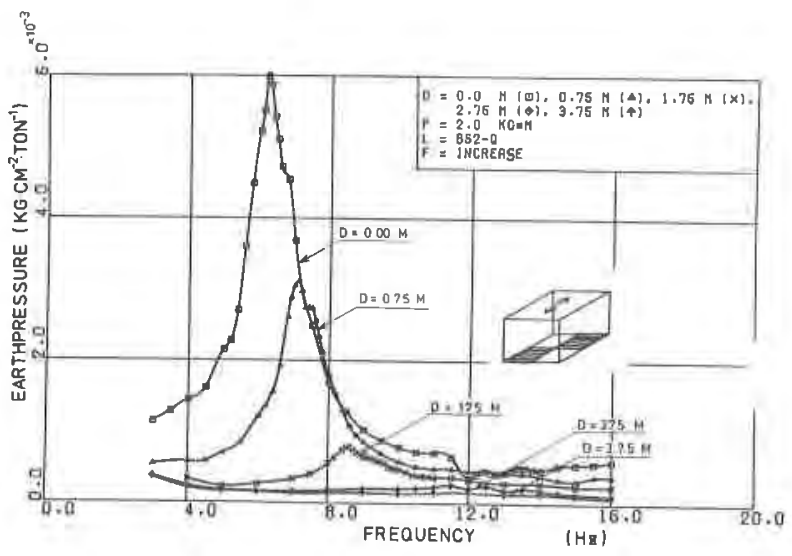

Fig. 6 Shear earth pressure response curves at bottom. 


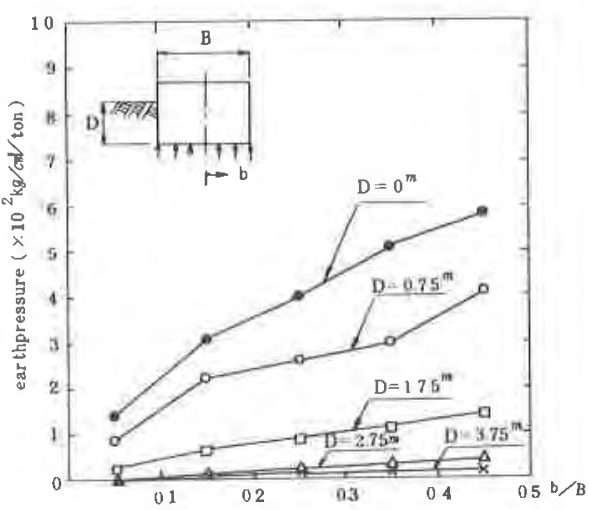

Fig.7 Distribution of normol earth pressure at bottom.

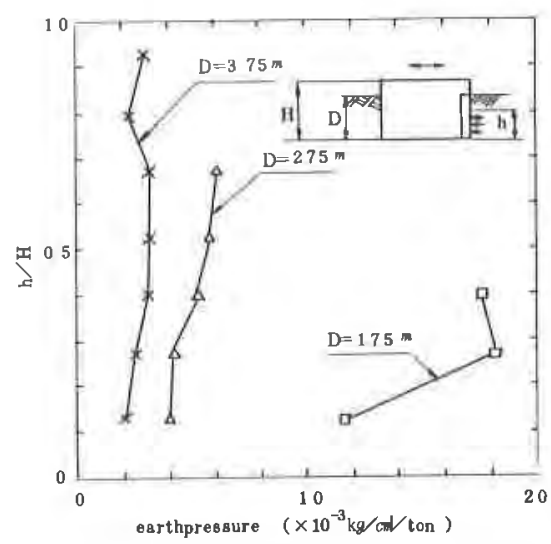

Fig.9 Distribution of normal earth pressure at side wall.

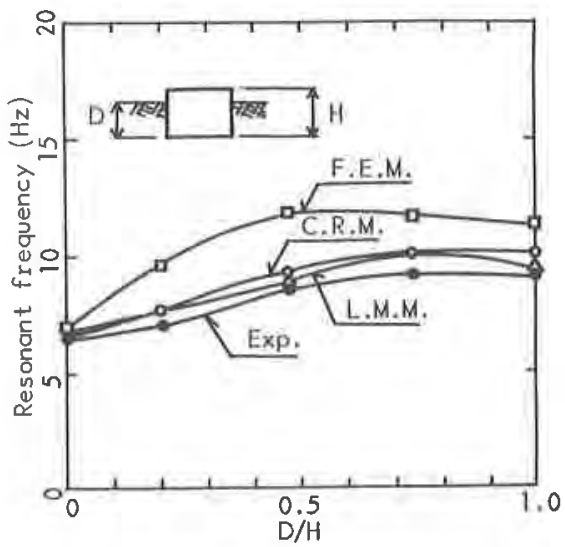

Fig. 14 Variety of resonant frequency.

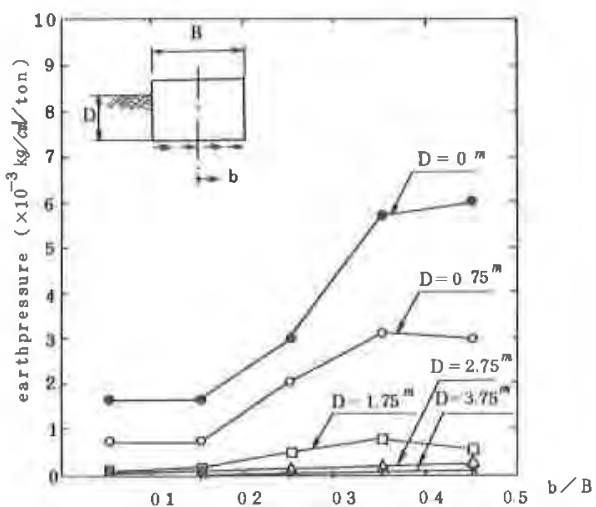

Fig.8 Distribution of shear earth pressure at bottom.

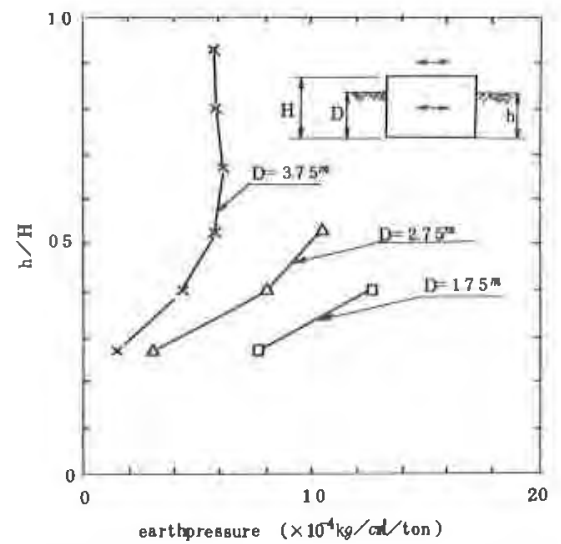

Fig. 10 Distribution of shear earth pressure at side wall.

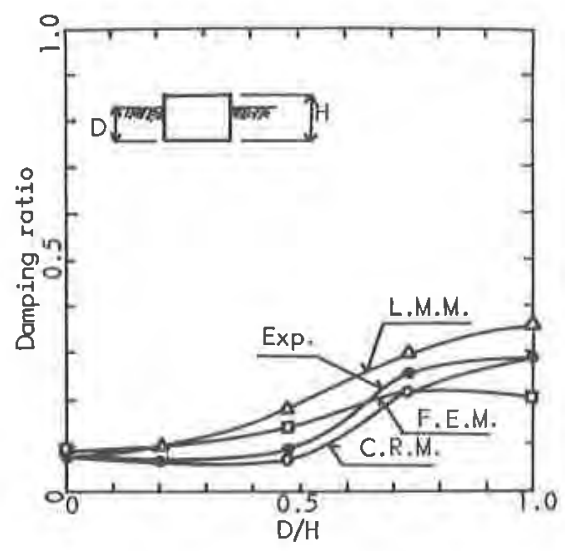

fig. 15 Variety of equated domping . 


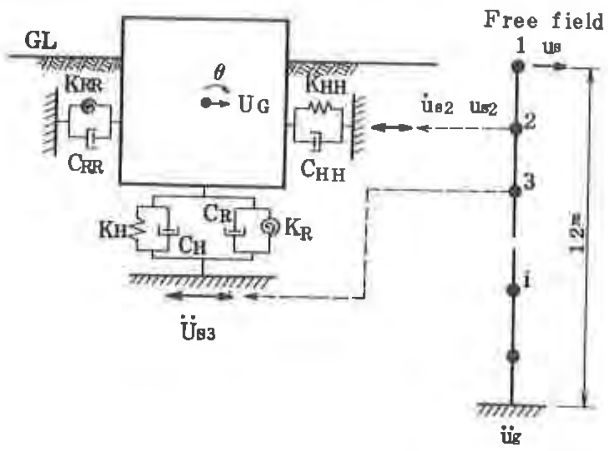

Fig. 11 Lumped mass model.
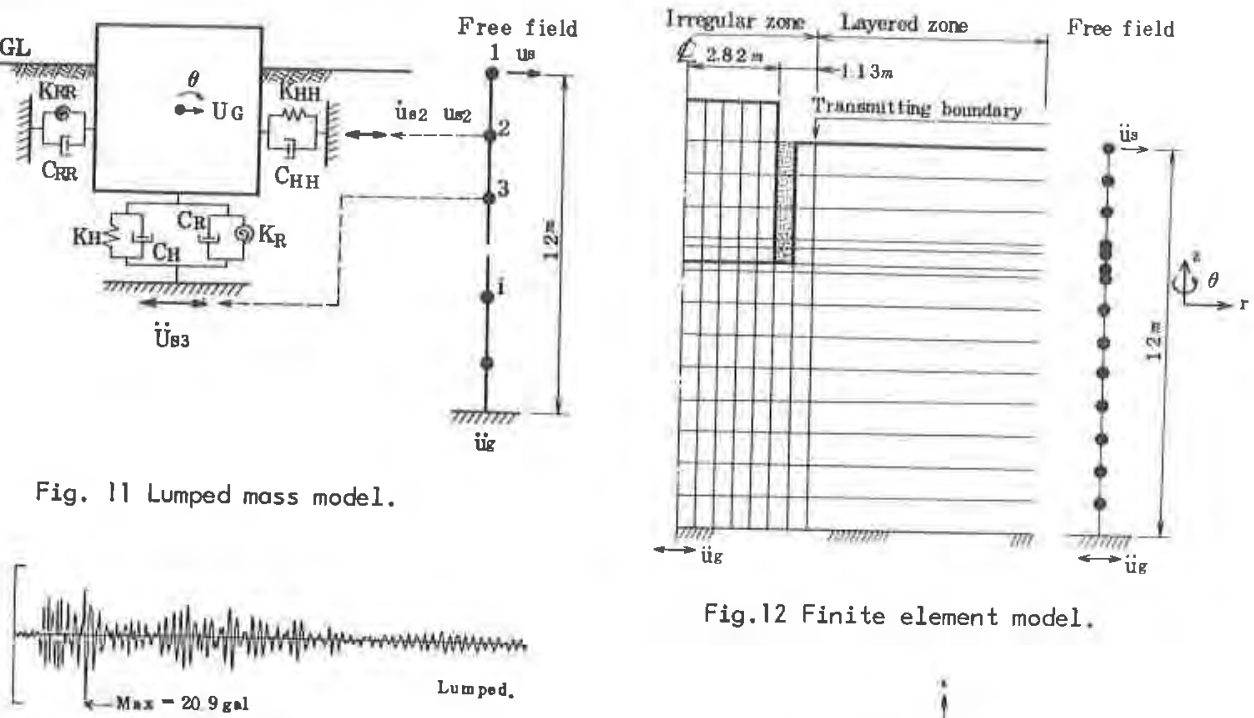

Fig. 12 Finite element model.

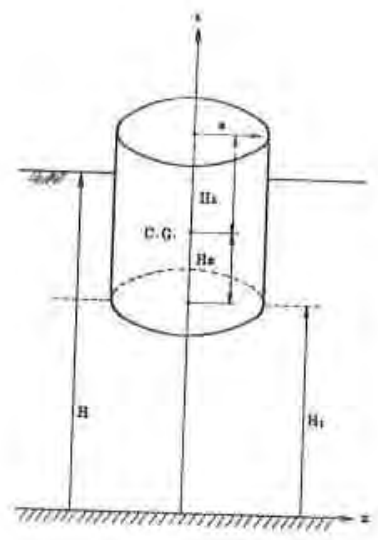

Fig. 13 Cylindrical rigid model.

Fig.16 Time history response during ear thquake.

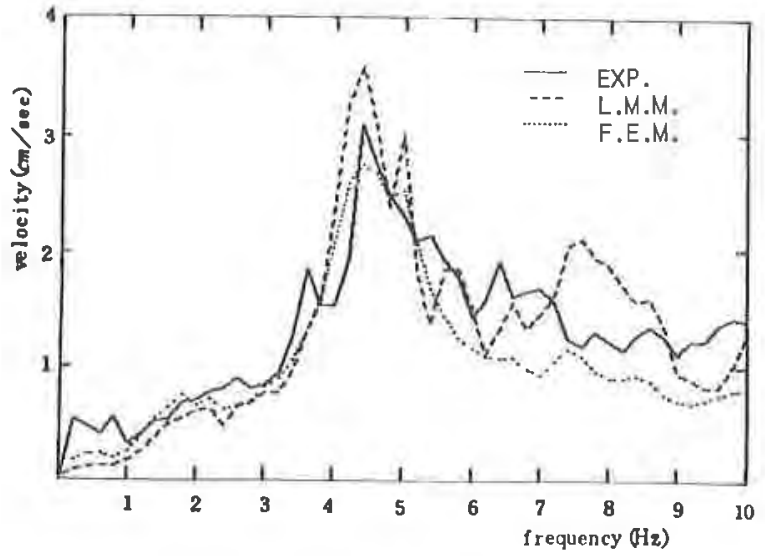

Fig. 17 Response spectro of time history during earthquake. 